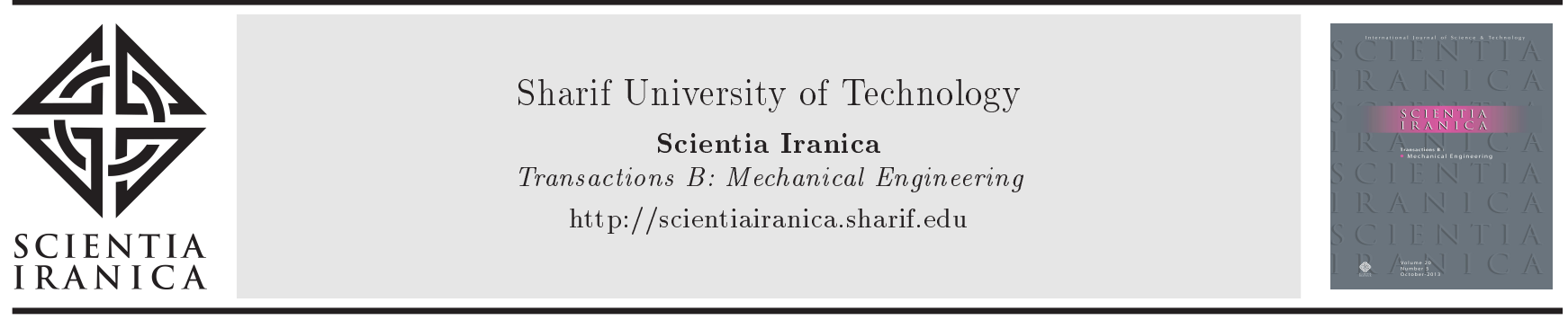

\title{
Optimization of friction stir welding parameters with Taguchi method for maximum electrical conductivity in Al-1080 welded sections
}

\author{
R. Delir Nazarlou ${ }^{\mathrm{a}}$, B. Nemati Akhgar ${ }^{\mathrm{b}}$, and F. Omidbakhsh ${ }^{\mathrm{a}, *}$ \\ a. Department of Mechanical Engineering, College of Engineering, Tabriz Branch, Islamic Azad University, Tabriz, Iran. \\ b. Department of Mining Engineering, Engineering Faculty, Urmia University, Urmia, P.O. Box 57561/51818, Iran.
}

Received 1 August 2020; received in revised form 14 October 2020; accepted 21 March 2021

\author{
KEYWORDS \\ Taguchi method; \\ Electrical \\ conductivity; \\ Welding parameters; \\ ANOVA test; \\ 1080 aluminum.
}

\begin{abstract}
This paper attempts to optimize welding parameters. The strength and quality of $\mathrm{FSW}_{e d}$ (Friction Stir Welding) sections are affected by materials transfer, work hardening, and transformations. These properties depend strongly on materials transfer, which is under the control of welding parameters. The soundness of friction stir welded sections is usually studied by Non Destructive Test (NDT) techniques. However, it could be characterized by physical properties such as electrical conductivity. The higher electrical conductivity implies less defects and higher welding quality. For this purpose, the Taguchi $L_{9}$ orthogonal design of experiment was used to optimize the welding parameters. The optimum process parameters and their effectiveness in the electrical conductivity of welded sections were analyzed by Signal-to-Noise $(S / N)$ ratio and Analysis Of Variance (ANOVA) tests. The results indicated that the tilt angle and tool shape were the most influential parameters to catch the maximum conductivity in welded joints. The optimum tool shape and tilt angle were cylindrical and $3^{\circ}$, respectively. The optimum conditions for welding and rotational speeds were characterized by $100 \mathrm{~mm} / \mathrm{min}$ and $900 \mathrm{rpm}$ in the stir zone, $250 \mathrm{~mm} / \mathrm{min}$ and $900 \mathrm{rpm}$ in Advancing Side (AS), and $100 \mathrm{~mm} / \mathrm{min}$ and $450 \mathrm{rpm}$ in Retreating Side (RS), respectively.

(C) 2021 Sharif University of Technology. All rights reserved.
\end{abstract}

\section{Introduction}

Friction Stir Welding (FSW) as a solid state joining technique was developed by TWI in 1991 [1]. In FSW, a non-consumable tool rotates between two parts at a constant speed [2]. The rotation of a pin provides frictional heat that facilitates the transfer of material by hot deformation of plasticized materials [3]. Joining process with FSW is based on the deformed material

*. Corresponding author.

E-mail addresses: F.Omidbakhsh@gmail.com and

Farazomidbakhsh@iaut.ac.ir (F.Omidbakhsh)

doi: $10.24200 /$ sci.2021.56528.4772 deposition behind the rotating tool [4]. This welding technique is suitable for materials such as aluminum, magnesium, and titanium. These alloys are well known for their poor weldability by conventional fusion welding techniques $[5,6]$.

In the last decade, many researches have been carried out on the FSW mechanism to provide an insight into the effects of process parameters on material transfer mechanism, microstructure variation, and mechanical properties of welded joints $[7,8]$.

In the FSW process, several parameters affect the soundness and strength of welded parts involving welding speed, rotational speed, tilt angle, tool shape, etc. $[9,10]$. The effects of process parameters on welds properties have been investigated with a series 
of classical experimental test methods; however, their interactions have not been studied. Although the effects of these parameters on the joint properties have been well-approved [11,12], their simultaneous effects on the weld properties have not been well evaluated. In recent years, several attempts have been made to optimize the welding parameters with Design of Experiment (DOE) and Taguchi method [13,14]. The DOE is an effective way to maximize the volume of data collection and reduce the number of trials. Recently, Shunmugasundaram et al. [15] studied the effects of rotational speed, welding speed, and tilt angle on the tensile strength of Al-5052 and 6063 alloys by Taguchi $L_{9}$ orthogonal design. The results have confirmed that the Taguchi design could be a very useful method to predict the modified conditions of the welding process.

Regarding the developments of experimental study methods in recent years, the statistical experimental designs have been employed for a more efficient analysis of various systems [16]. The statistical experimental design provides maximum data with high reliability through fewer experiments and leads to greater time saving and cost reduction. Goyal and Garg [17] studied the strength of $\mathrm{FSW}_{\text {ed }}$ aluminum welded plates by Taguchi method with 5 factors and 6 levels. Their research approved that the Taguchi design could be a strong tool to predict the modified welding conditions. In Taguchi design, the optimum conditions could be obtained in three statuses based on the desired target of response such as "smaller is better", "larger is better", or "nominal is best". Simple statistical tools of Signal-to-Noise ratio $(S / N)$ and analysis of variance (ANOVA) are usually used with Taguchi design. The statistical methods are the main tools for predicting optimal conditions and influence of each factor on responses $[18,19]$. These analyses would provide very useful information about the main effective parameters in the tests and their mutual interactions.

It is well known that the electrical conductivity of metals desponds on the phase distribution, grain size, lattice defects density, point defects, dislocations density, impurity concentration, residuals stresses, and mechanical strains [20]. On the other hand, the phase transformations during the FSW process that provide different zones involving Thermo-Mechanical Affected Zone (TMAZ), Heat Affected Zone (HAZ), and re- crystallized regions affect the electrical conductivity significantly [21]. All of these phenomena are affected by FSW parameters and number of heat inputs.

In aluminum alloys, the effects of phase transformations in TMAZ and HAZ zones lead to coarse deformed recrystallized grains and some second-phase precipitations $[22,23]$. In aluminum alloys, secondphase precipitation is the most important strengthening process that has prominent effects on the physical and mechanical behavior of these alloys [24].

As mentioned above, defects density and phase transformation affect the electrical conductivity of $\mathrm{FSW}_{e d}$ aluminum parts. Therefore, electrical conductivity could be used as an indirect and non-destructive method for welded parts quality characterization. In the last years, several attempts have been made to study the electrical resistivity variations due to FSW $[20,25]$. However, the electrical resistivity fluctuation by welding parameters variation has not been studied completely and there is not a comprehensive understanding in this regard.

In this study, to prevent the precipitation and phase transformation effects on the electrical conductivity of $\mathrm{FSW}_{e d}$ parts, pure commercial aluminum alloy was used. In order to optimize the electrical conductivity, an effort has been made to optimize the FSW parameters of 1080 alloy using Taguchi analysis. The aim was to investigate the effects of welding parameters including tool shape, tilt angle, welding speed, and rotational speed on the electrical conductivity of welded sections. For this purpose, the Taguchi method was employed to predict the main effective parameter and finally, to define an optimized condition; the results were reviewed by $S / N$ ratio analysis.

\section{Experimental methods}

\subsection{Selection of materials}

In this research, samples were prepared from 1080 aluminum alloy. Its chemical composition was analyzed by Spark Emission Spectrometer and the resulting analysis is presented in Table 1 .

This alloy is widely used in the electrical and chemical industries due to its high corrosion resistance with high thermal and electrical conductivity [26].

Other characteristics of this series are excellent

Table 1. The chemical composition of AA1080.

\begin{tabular}{|c|c|c|c|c|c|c|c|c|c|c|c|}
\hline \multirow[b]{3}{*}{ Content (Wt. \%) } & \multicolumn{11}{|c|}{ Elements } \\
\hline & $\mathrm{Si}$ & $\mathrm{Fe}$ & $\mathrm{Cu}$ & $\mathrm{Mn}$ & $\mathrm{Mg}$ & $\mathrm{Zn}$ & $\mathrm{Cr}$ & $\mathrm{Ni}$ & $\mathrm{Ti}$ & $\mathrm{Be}$ & $\mathrm{Ca}$ \\
\hline & 0.08 & 0.14 & 0.01 & 0.007 & 0.03 & 0.01 & 0.005 & 0.007 & 0.012 & None & Trace \\
\hline & \multicolumn{11}{|c|}{ Elements } \\
\hline & $\mathrm{Pb} \%$ & $\mathrm{Sn} \%$ & $\mathrm{Sr} \%$ & $\mathrm{~V} \%$ & $\mathrm{Na} \%$ & $\mathrm{Bi} \%$ & $\mathrm{Zr} \%$ & $\mathrm{~B} \%$ & $\mathrm{Ga} \%$ & $\mathrm{Li} \%$ & $\mathrm{~A} 1 \%$ \\
\hline Content (Wt. \%) & Trace & $<0.002$ & None & 0.013 & Trace & $<0.003$ & 0.005 & 0.0005 & 0.01 & None & Balance \\
\hline
\end{tabular}


workability and low mechanical properties [17]; however, the strength and mechanical properties could be slightly improved with strain hardening [26]. These alloys are designated as non-heat treatable [27] and their microstructure is precipitate free [28]. Therefore, the electrical conductivity variation after the FSW would not be affected due to the precipitation or ageing processes, which are the dominant strengthening mechanisms in aluminum alloys.

\subsection{Samples and welding tools preparation}

The plate lamination was checked by Ultrasonic Testing (UT) method. Samples were cut out by a wire cutter machine in the rolling direction with the dimensions $150 \times 50 \times 10 \mathrm{~mm}$. The FSW tools were built of H13 tools steel and were heat treated to the final hardness of 52HRc. The tools shape and dimensions are shown in Figure 1.

\subsection{Taguchi method}

For experimental design by Taguchi, four factors involving tool shape, tilt angle, welding speed, and rotational speed were considered at three levels. The selected parameters and levels for Taguchi design in these experiments are presented in Table 2. Numbers 1, 2, and 3 exhibit the lowest, mid, and highest levels,
Table 3. $L_{9}(34)$ orthogonal array of Taguchi design and arrangement of selected parameters.

\begin{tabular}{ccccc}
\hline Exp. no. & $\begin{array}{c}\text { Tool } \\
\text { shape }\end{array}$ & $\begin{array}{c}\text { Tilt } \\
\text { angle }\end{array}$ & $\begin{array}{c}\text { Welding } \\
\text { speed }\end{array}$ & $\begin{array}{c}\text { Rotational } \\
\text { speed }\end{array}$ \\
\hline 1 & 1 & 1 & 1 & 1 \\
2 & 1 & 2 & 2 & 2 \\
3 & 1 & 3 & 3 & 3 \\
4 & 2 & 1 & 2 & 3 \\
5 & 2 & 2 & 3 & 1 \\
6 & 2 & 3 & 1 & 2 \\
7 & 3 & 1 & 3 & 2 \\
8 & 3 & 2 & 1 & 3 \\
9 & 3 & 3 & 2 & 1 \\
\hline
\end{tabular}

respectively. Four parameters at three levels mean that the $L_{9}$ (34) orthogonal array of Taguchi design must be randomly performed in 9 runs (Table 3 ). The $S / N$ ratio and ANOVA analysis were used for evaluation of optimum conditions.

\subsection{Experimental procedure}

The welding procedure was done by a vertical milling machine equipped with a special fixture to restrain the
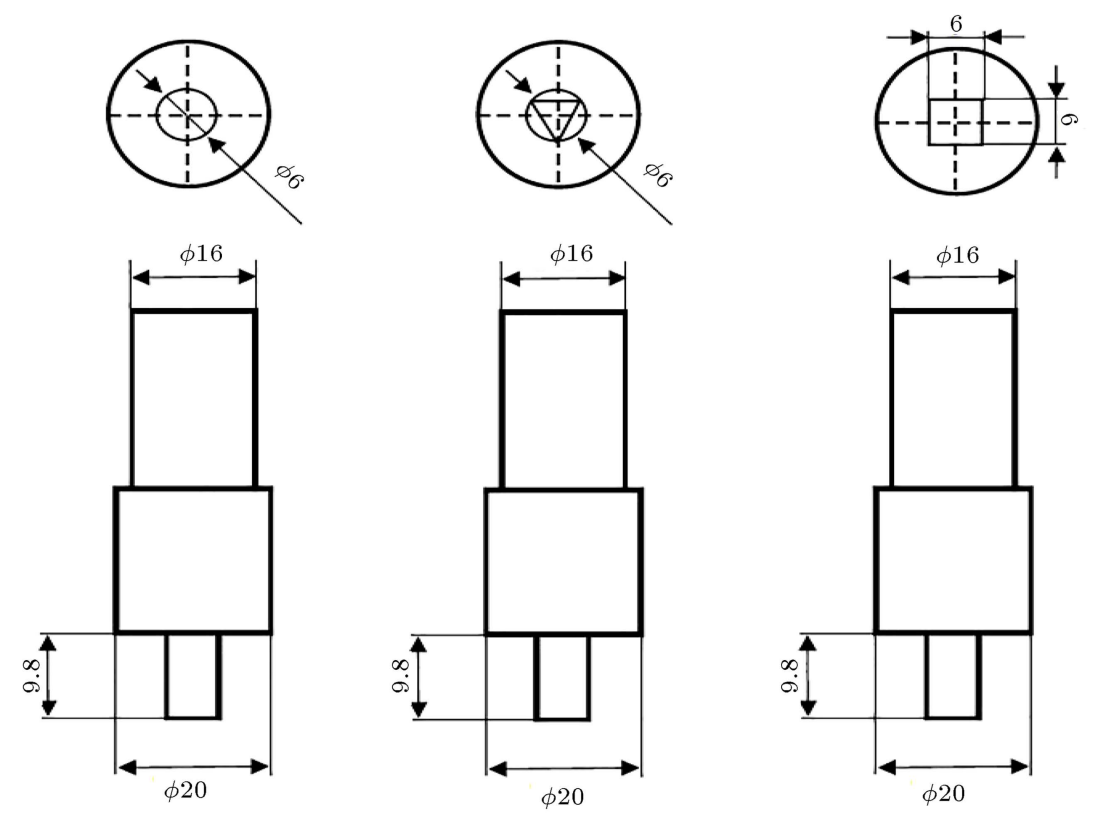

Figure 1. Tool design and dimensions of Friction Stir Welding (FSW) prepared in the welding process.

Table 2. Process parameters and their levels used in the experiments.

\begin{tabular}{ccccc}
\hline Parameters & Symbol & Level 1 & Level 2 & Level 3 \\
\hline Tool shape & TS & Cylindrical & Square & Triangle \\
Tilt angle & TA & 1 degree & 2 degrees & 3 degrees \\
Welding speed & WS & $100 \mathrm{~mm} / \mathrm{min}$ & $160 \mathrm{~mm} / \mathrm{min}$ & $250 \mathrm{~mm} / \mathrm{min}$ \\
Rotational speed & RS & $450 \mathrm{rpm}$ & $900 \mathrm{rpm}$ & $1120 \mathrm{rpm}$ \\
\hline
\end{tabular}




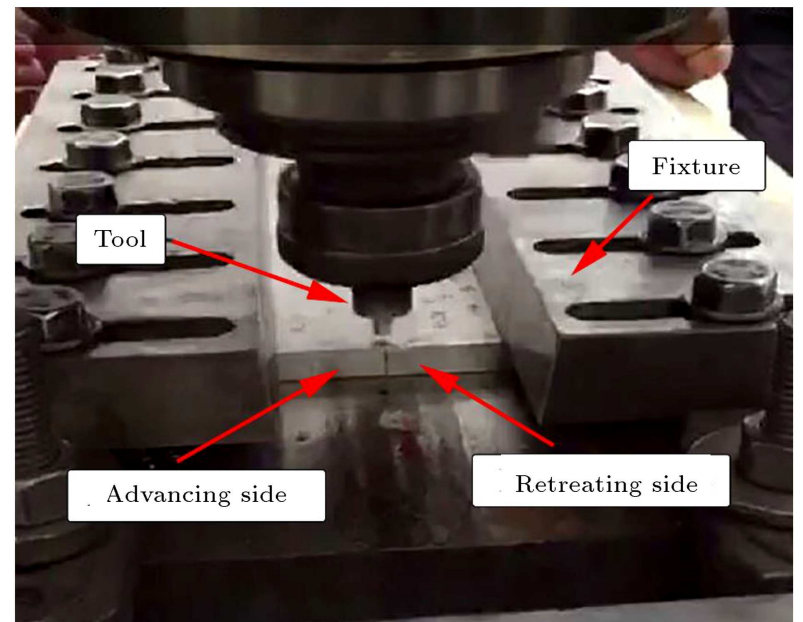

Figure 2. Friction stir welding setup used for welding of aluminum samples.

samples. The FSW setup used in this experiment is shown in Figure 2. The cross-section of the welded specimen is presented in Figure 3.

The electrical conductivity of welded samples was measured using the Signatone S-302-4 four-point probe station with $1.6 \mathrm{~mm}$ probe spacing. The electrical conductivity measurements were separately conducted in three regions: Advancing Side (AS), Retreating Side (RS), and Stir Zone (SZ).

\section{Results and discussion}

\subsection{Analysis of experimental data}

As mentioned above, a $L_{9}$ Taguchi orthogonal array was applied to experimental design step to study the influence of selected parameters on the electrical conductivity. The results acquired from electrical conductivity measurements are presented in Tables 4-6. After $L_{9}$ performance, the results were used to calculate the $S / N$ ratios to predict optimum conditions.

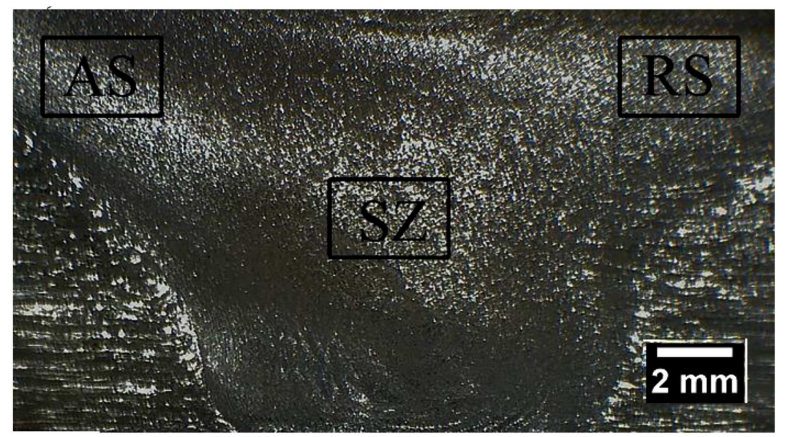

(a)

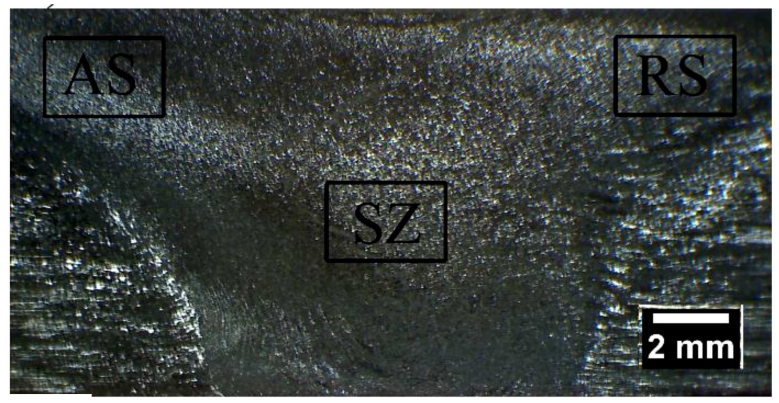

(b)

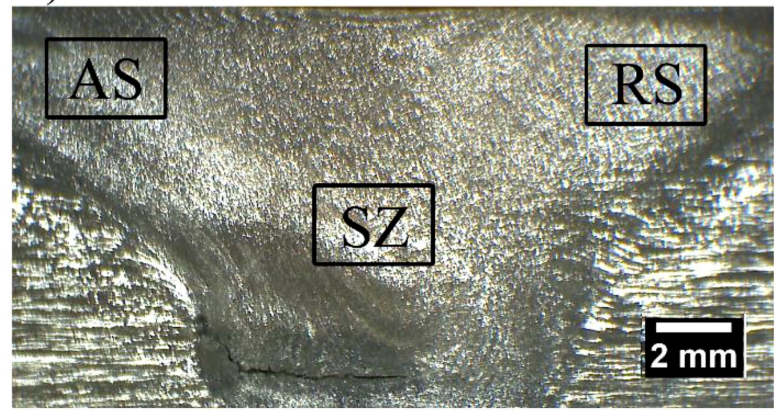

(c)

Figure 3. Welded zone structure: (a) Exp. No. 3, (b) Exp. No. 6, and (c) Exp. No. 9.

Table 4. Measured electrical conductivities in the stir zone and their $S / N$ ratio.

\begin{tabular}{|c|c|c|c|c|c|}
\hline $\begin{array}{c}\text { Exp. } \\
\text { no. }\end{array}$ & $\begin{array}{c}\text { Electrical } \\
\text { conductivity } 1 \\
\text { "S/m" } \\
\mathrm{SZ}^{\mathrm{a}}\end{array}$ & $\begin{array}{c}\text { Electrical } \\
\text { conductivity } 2 \\
\text { "S/m" } \\
\mathrm{SZ}\end{array}$ & $\begin{array}{c}\text { Electrical } \\
\text { conductivity } 3 \\
\text { "S/m" } \\
\mathrm{SZ}\end{array}$ & $\begin{array}{c}\text { Electrical } \\
\text { conductivity (mean) } \\
\text { "S/m" } \\
\mathrm{SZ} \\
\end{array}$ & $S / N$ mean \\
\hline 1 & 305716.9 & 305343.5 & 304971 & 305343.8 & 109.696 \\
\hline 2 & 597728.9 & 595947.5 & 598444 & 597373.5 & 115.525 \\
\hline 3 & 1008064.5 & 1005025.1 & 1002004 & 1005031.2 & 120.044 \\
\hline 4 & 139742.8 & 139684.3 & 139840.5 & 139755.9 & 102.907 \\
\hline 5 & 541711.8 & 542888.1 & 542299.3 & 542299.7 & 114.685 \\
\hline 6 & 795544.9 & 793650.7 & 792393 & 793862.9 & 117.995 \\
\hline 7 & 225733.6 & 225631.7 & 225326.7 & 225564 & 107.065 \\
\hline 8 & 501253.1 & 502260.1 & 500000 & 502260.1 & 114.019 \\
\hline 9 & 626566.4 & 628535.5 & 625000 & 626700.6 & 115.941 \\
\hline
\end{tabular}

${ }^{\mathrm{a}} \mathrm{SZ}$ : Stir Zone. 
Table 5. Measured electrical conductivities in the advancing side and their $S / N$ ratio.

\begin{tabular}{|c|c|c|c|c|c|}
\hline $\begin{array}{c}\text { Exp. } \\
\text { no. }\end{array}$ & $\begin{array}{c}\text { Electrical } \\
\text { conductivity } 1 \\
\text { "S/m" } \\
\mathrm{AS}^{\mathrm{a}}\end{array}$ & $\begin{array}{c}\text { Electrical } \\
\text { conductivity } 2 \\
\text { "S/m" } \\
\text { AS }\end{array}$ & $\begin{array}{c}\text { Electrical } \\
\text { conductivity } 3 \\
\text { "S/m" } \\
\text { AS }\end{array}$ & $\begin{array}{c}\text { Electrical } \\
\text { conductivity (mean) } \\
\text { "S/m" } \\
\text { AS }\end{array}$ & $S / N$ mean \\
\hline 1 & 311138.7 & 310752 & 310559 & 310816.6 & 109.850 \\
\hline 2 & 1262626.2 & 1257861.6 & 1253132.8 & 1257874 & 121.993 \\
\hline 3 & 1386962.5 & 1381215.4 & 1375515.8 & 1381231 & 122.805 \\
\hline 4 & 145751.3 & 145645.2 & 145708.8 & 145701.8 & 103.269 \\
\hline 5 & 738007.3 & 740192.4 & 735835.1 & 738011.7 & 117.361 \\
\hline 6 & 918273.6 & 922509.2 & 925069.3 & 921950.8 & 119.294 \\
\hline 7 & 239808.1 & 239635.7 & 239348.9 & 239597.6 & 107.590 \\
\hline 8 & 648929.2 & 648088.1 & 645577.7 & 647531.7 & 116.225 \\
\hline 9 & 842459.9 & 846023.6 & 843881.8 & 844121.8 & 118.528 \\
\hline
\end{tabular}

aS: Advancing Side.

Table 6. Measured electrical conductivities the retreating side and their $S / N$ ratio.

\begin{tabular}{|c|c|c|c|c|c|}
\hline $\begin{array}{c}\text { Exp. } \\
\text { no. }\end{array}$ & $\begin{array}{c}\text { Electrical } \\
\text { conductivity } 1 \\
\text { "S/m" } \\
\mathrm{RS}^{\mathrm{a}} \\
\end{array}$ & $\begin{array}{c}\text { Electrical } \\
\text { conductivity } 2 \\
\text { "S/m" } \\
\text { RS }\end{array}$ & $\begin{array}{c}\text { Electrical } \\
\text { conductivity } 3 \\
\text { "S/m" } \\
\text { RS } \\
\end{array}$ & $\begin{array}{c}\text { Electrical } \\
\text { conductivity (mean) } \\
\text { "S/m" } \\
\text { RS }\end{array}$ & $S / N$ mean \\
\hline 1 & 301295.5 & 301659.1 & 301932.3 & 301629 & 109.589 \\
\hline 2 & 540540.5 & 539374.3 & 537923.6 & 539279.5 & 114.636 \\
\hline 3 & 583771.1 & 582750.5 & 581733.5 & 582751.8 & 115.310 \\
\hline 4 & 127404.7 & 127485.9 & 127437.2 & 127442.7 & 102.106 \\
\hline 5 & 496277.9 & 497265 & 495294.7 & 496279.2 & 113.915 \\
\hline 6 & 596658.7 & 598444 & 595592.6 & 596898.5 & 115.518 \\
\hline 7 & 157232.7 & 157133.8 & 157035.1 & 157133.9 & 103.925 \\
\hline 8 & 334112.9 & 333667 & 333444.4 & 333741.5 & 110.468 \\
\hline 9 & 469924.8 & 471475.7 & 470588.2 & 470662.9 & 113.454 \\
\hline
\end{tabular}

${ }^{a}$ RS: Retreating Side.

The $S / N$ analysis was performed to find the optimized condition. Since the target of the study is to optimize the welding parameters to catch the welding condition with the highest electrical conductivity, the corresponding $S / N$ ratio analysis was performed using "larger is better" approach. The $S / N$ ratio was calculated through Eq. (1) [18]:

$$
S / N=-10 \log \left(\frac{1}{n} \sum_{i=1}^{n} \frac{1}{y_{i}^{2}}\right)
$$

where $y_{i}$ is the electrical conductivity obtained from the experiments and $n$ is the number of repetitions. The mean $S / N$ ratios for each level of parameters were computed to realize optimum conditions using Minitab software (Figures 4-6).

The electrical conductivity $\left(y_{i}\right)$ and calculated $S / N$ ratio of AS, RS, and SZ are presented separately in

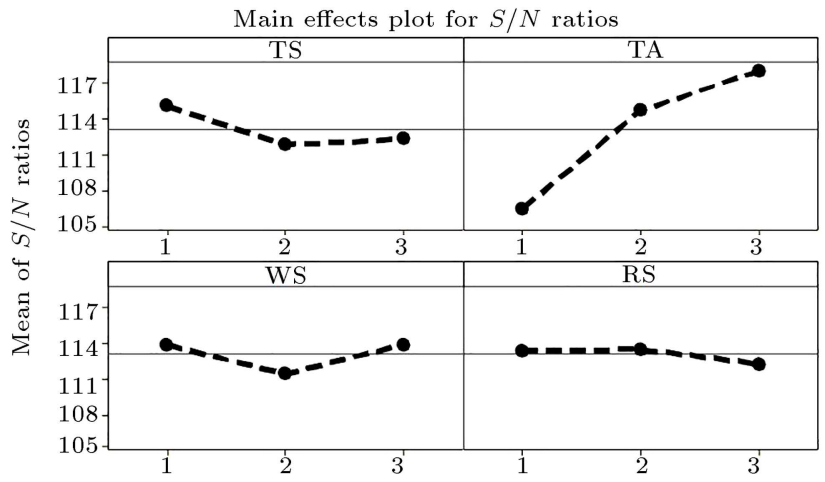

Signal-to-noise: Larger is better

Figure 4. Plots of process parameters effect $(S / N$ ratio) in the stir zone.

Tables 4-6. The mean $S / N$ ratios for each level of every parameter were computed to evaluate the optimum conditions by Eq. (2) as follows [18]: 


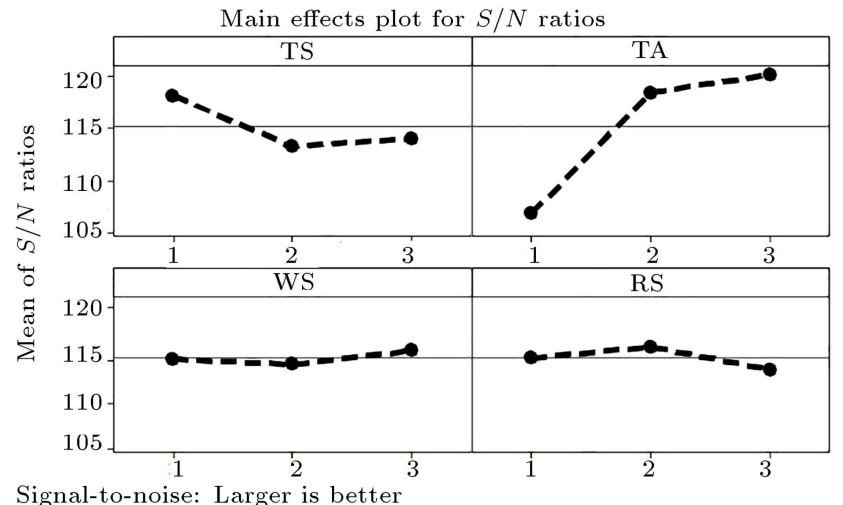

Figure 5. Plots of process parameters effect $(S / N$ ratio) in the Advancing Side (AS).

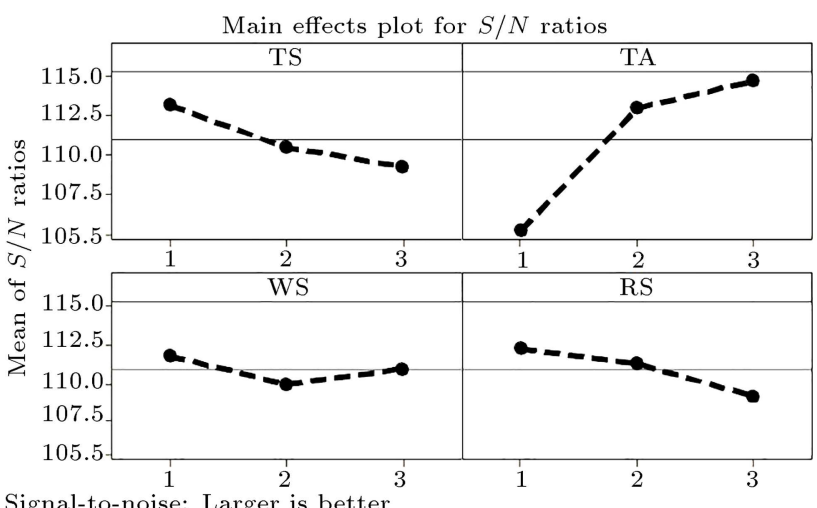

Figure 6. Plots of process parameters effect $(S / N$ ratio) in the Retreating Side (RS).

$$
T S 1=\frac{\operatorname{Exp} .1+\operatorname{Exp} .2+\operatorname{Exp} .3}{3},
$$

for example:

$$
\begin{aligned}
T S 1 & =\frac{\text { Exp.1+Exp.2+Exp.3 }}{3} \\
& =\frac{109.696+115.525+120.044}{3}=115.086, \\
T A 2 & =\frac{\text { Exp.1+Exp.2+Exp.3 }}{3} \\
& =\frac{115.525+114.685+114.019}{3}=114.743 .
\end{aligned}
$$

The mean $S / N$ ratio for each level of parameters is shown in Figures 4-6. The highest value of mean $S / N$ ratio for a parameter was considered as the optimum level of relative parameter. Therefore, it is clear that the optimum conditions are TS1, TA3, WS3, and RS2.

As described earlier, the highest value of $S / N$ ratio needs to be considered as the optimum condition. Therefore, it is clear that the optimum condition was cylindrical shape for the tool and 3 degrees of tilt angle in all of the three zones. The achieved optimum conditions for Taguchi method proved that the parameters of welding and rotation speed behaved in different ways in AS, RS, and SZ. The optimum conditions for welding speed and rotation speed were $100 \mathrm{~mm} / \mathrm{min}$ and $900 \mathrm{rpm}$ for SZ, $250 \mathrm{~mm} / \mathrm{min}$ and $900 \mathrm{rpm}$ for AS, and $100 \mathrm{~mm} / \mathrm{min}$ and $450 \mathrm{rpm}$ for RS, respectively.

The $S / N$ ratio at each level for a parameter is calculated using Eq. (2) [18]. The difference between the maximum and minimum of $S / N$ ratio in each parameter verified the effectiveness of that parameter in the process [18]. According to Table 7, the effectiveness order of welding parameters in the electrical conductivity in the SZ is tilt angle, tool shape, welding speed, and rotational speed.

The results revealed that the welding parameters in RS and AS differed compared with the SZ. According to Tables 8 and 9 , the effectiveness order in these areas is as follows: tilt angle, tool shape, rotational speed, and welding speed. The result demonstrated that the welding speed was more effective than rotational speed in the SZ.

It is believed that this difference results from the materials transfer mechanism. It seems that the main parameter affecting the material transfer under the pin is the welding speed. However, the main material transfer mechanism around the pin (meaning RS and AS zones) is the pin rotation. It is well known that the pin rotation provides the required shearing stresses in materials deformation and transfer [29]. ANOVA outcomes have confirmed the results obtained from $S / N$ ratios calculations (Tables $10-12$ ).

The ANOVA results proved that the effects of tilt

\begin{tabular}{|c|c|c|c|c|c|c|c|c|c|c|c|c|}
\hline & TS1 & TS2 & TS3 & TA1 & TA2 & TA3 & WS1 & WS2 & WS3 & RS1 & RS2 & RS3 \\
\hline$S / N$ & 109.696 & 102.907 & 107.065 & 109.696 & 115.525 & 120.044 & 109.696 & 115.525 & 120.044 & 109.696 & 115.525 & 120.044 \\
\hline$S / N$ & 115.525 & 114.685 & 114.019 & 102.907 & 114.685 & 117.995 & 117.995 & 102.907 & 114.685 & 114.685 & 117.995 & 102.907 \\
\hline$S / N$ & 120.044 & 117.995 & 115.941 & 107.065 & 114.019 & 115.941 & 114.019 & 115.941 & 107.065 & 115.941 & 107.065 & 114.019 \\
\hline $\begin{array}{l}\text { Mean in } \\
\text { each level }\end{array}$ & 115.086 & 111.862 & 112.341 & 106.556 & 114.743 & 117.993 & 113.903 & 111.457 & 113.931 & 113.440 & 113.528 & 112.323 \\
\hline Max-min & & 3.224 & & & 11.437 & & & 2.536 & & & 1.205 & \\
\hline Rank & & 2 & & & 1 & & & 3 & & & 4 & \\
\hline
\end{tabular}
angle, tool shape, welding speed, and rotational speed on the electrical conductivity of the SZ were $85.11 \%$,

Table 7. The arrangement of calculated $S / N$ ratios and mean of $S / N$ ratios at each level to compute optimum conditions in the stir zone. 
Table 8. The arrangement of the calculated $S / N$ ratios and mean of $S / N$ ratios at each level to compute optimum conditions in the advancing side.

\begin{tabular}{|c|c|c|c|c|c|c|c|c|c|c|c|c|}
\hline & TS1 & TS2 & TS3 & TA1 & TA2 & TA3 & WS1 & WS2 & WS3 & RS1 & RS2 & RS3 \\
\hline$S / N$ & 109.850 & 103.269 & 107.590 & 109.850 & 121.993 & 122.805 & 109.850 & 121.993 & 122.805 & 109.850 & 121.993 & 122.805 \\
\hline$S / N$ & 121.993 & 117.361 & 116.225 & 103.269 & 117.361 & 119.294 & 119.294 & 103.269 & 117.361 & 117.361 & 119.294 & 103.269 \\
\hline$S / N$ & 122.805 & 119.294 & 118.528 & 107.590 & 116.225 & 118.528 & 116.225 & 118.528 & 107.590 & 118.528 & 107.590 & 116.225 \\
\hline $\begin{array}{l}\text { Mean in } \\
\text { each level }\end{array}$ & 118.216 & 113.308 & 114.114 & 106.903 & 118.526 & 120.209 & 115.123 & 114.596 & 115.918 & 115.246 & 116.292 & 114.099 \\
\hline Max-min & & 4.908 & & & 13.306 & & & 1.322 & & & 2.193 & \\
\hline Rank & & 2 & & & 1 & & & 4 & & & 3 & \\
\hline
\end{tabular}

Table 9. The arrangement of calculated $S / N$ ratios and mean of $S / N$ ratios at each level to compute optimum conditions in the retreating side.

\begin{tabular}{|c|c|c|c|c|c|c|c|c|c|c|c|c|}
\hline & TS1 & TS2 & TS3 & TA1 & TA2 & TA3 & WS1 & WS2 & WS3 & RS1 & RS2 & RS3 \\
\hline$S / N$ & 109.589 & 102.106 & 103.925 & 109.589 & 114.636 & 115.310 & 109.589 & 114.636 & 115.310 & 109.589 & 114.636 & 115.310 \\
\hline$S / N$ & 114.636 & 113.915 & 110.468 & 102.106 & 113.915 & 115.518 & 115.518 & 102.106 & 113.915 & 113.915 & 115.518 & 102.106 \\
\hline$S / N$ & 115.310 & 115.518 & 113.454 & 103.925 & 110.468 & 113.454 & 110.468 & 113.454 & 103.925 & 113.454 & 103.925 & 110.468 \\
\hline $\begin{array}{l}\text { Mean in } \\
\text { each level }\end{array}$ & 113.178 & 110.513 & 109.282 & 105.206 & 113.006 & 114.760 & 111.858 & 110.065 & 111.05 & 112.319 & 111.359 & 109.294 \\
\hline Max-min & & 3.896 & & & 9.554 & & & 1.793 & & & 3.025 & \\
\hline Rank & & 2 & & & 1 & & & 4 & & & 3 & \\
\hline
\end{tabular}

Table 10. Analysis Of Variance (ANOVA) analysis results for all the parameters in the stir zone.

\begin{tabular}{ccccc}
\hline Factor & DF & SS & MS & Contribution (\%) \\
\hline TS & 2 & 56363330959 & 28181665480 & 9.31 \\
TA & 2 & 515253000000 & 257626000000 & 85.11 \\
WS & 2 & 28132556258 & 14066278129 & 4.65 \\
RS & 2 & 5670556224 & 2835278112 & 0.94 \\
Total & 8 & 605419000000 & & 100 \\
\hline
\end{tabular}

Table 11. Analysis Of Variance (ANOVA) analysis results for all the parameters in the advancing side.

\begin{tabular}{ccccc}
\hline Factor & DF & SS & MS & Contribution (\%) \\
\hline TS & 2 & 311113000000 & 155557000000 & 20.52 \\
TA & 2 & 1117130000000 & 558567000000 & 73.67 \\
WS & 2 & 41815115296 & 20907557648 & 2.76 \\
RS & 2 & 46269756983 & 23134878942 & 3.05 \\
Total & 8 & 1516330000000 & & 100 \\
\hline
\end{tabular}

Table 12. Analysis Of Variance (ANOVA) analysis results for all the parameters in the retreating side.

\begin{tabular}{ccccc}
\hline Factor & DF & SS & MS & Contribution (\%) \\
\hline TS & 2 & 35767275380 & 17883637690 & 14.13 \\
TA & 2 & 202726000000 & 101363000000 & 80.08 \\
WS & 2 & 2086175712 & 1043087856 & 0.82 \\
RS & 2 & 12584597204 & 6292298602 & 4.97 \\
Total & 8 & 253164000000 & & 100 \\
\hline
\end{tabular}


$9.31 \%, 4.65 \%$, and $0.94 \%$, respectively. Also, the contribution parameters for the electrical conductivity in the AS were $73.67 \%, 20.52 \%, 3.05 \%, 2.76 \%$ and on the RS were $80.08 \%, 14.13 \%, 4.97 \%$, and $0.82 \%$ for tilt angle, tool shape, welding speed, and rotational speed, respectively.

\section{Conclusion}

This study investigated the effects of tool shape, tilt angle, rotational speed, and welding speed on the electrical conductivity of Al-1080 joint by using Taguchi method and Analysis Of Variance (ANOVA) analysis. Results of Signal-to-Noise $(S / N)$ analysis indicated that the optimal condition could be achieved for cylindrical pin and three-degree tilt angle. On the other hand, the optimum rotational speed and the welding speed in the stir zone and Advancing Side (AS) were $900 \mathrm{rpm}$ and $100 \mathrm{~mm} / \mathrm{min}$. However, in the retreating side, the optimum condition was characterized by $900 \mathrm{rpm}$ and $250 \mathrm{~mm} / \mathrm{min}$.

Based on $S / N$ ratio results, the effectiveness of parameters to achieve the maximum electrical conductivity in the stir zone was ordered as follows: tilt angle, tool shape, welding speed, and rotational speed. Moreover, in advancing and retreating sides, the effectiveness of parameters for maximum electrical conductivity was ordered as: tilt angle, tool shape, rotational speed and welding speed.

The main effective parameter for materials transfer mechanism under the pin was the welding speed; however, the main effective parameter for materials transfer mechanism around the pin was the rotational speed.

Finally, ANOVA analysis indicated that the effectiveness of tool shape, tilt angle, rotational speed, and welding speed parameters in the electrical conductivity of joint was $9.31 \%, 85.11 \%, 4.65 \%$, and $0.95 \%$ in the stir zone as well as $20.52 \%, 73.67 \%, 2.76 \%$, and $3.05 \%$ in the AS and $14.13 \%, 80.08 \%, 0.82 \%$, and $4.97 \%$ in the retreating side, respectively.

\section{Nomenclature}

$\begin{array}{ll}\text { TS } & \text { Tool Shape } \\ \text { TA } & \text { Tilt Angle } \\ \text { WS } & \text { Welding Speed } \\ \text { RS } & \text { Rotational Speed } \\ \text { SZ } & \text { Stir Zone } \\ \text { AS } & \text { Advancing Side } \\ \text { RS } & \text { Retreating Side } \\ \text { ANOVA } & \text { Analysis Of Variance } \\ \text { DOE } & \text { Design Of Experiment } \\ \text { S/m } & \text { Siemens per meter }\end{array}$

$\begin{array}{ll}S / N & \text { Signal-to-Noise ratio } \\ y_{i} & \begin{array}{l}\text { Electrical conductivity obtained from } \\ \text { the experiments }\end{array} \\ n & \text { The number of repetitions } \\ \text { DOF } & \text { Degree of Freedom } \\ \text { SS } & \text { Sum of Squares of treatments } \\ \text { MS } & \text { Mean Square }\end{array}$

\section{References}

1. Mishra, R.S. and Ma, Z.Y. "Friction stir welding and processing", Materials Science and Engineering., 50(1-2), pp. 1-78 (2005).

2. Sato, Y.S., Urata, M., and Kokawa, H. "Parameters controlling microstructure and hardness during friction-stir welding of precipitation-hardenable aluminum alloy 6063", Metallurgical and Materials, Transactions A., 33(3), pp. 625-635 (2002).

3. Colligan, K. "Material flow behavior during friction welding of aluminum", Weld J., 75(7), pp. 229s-237s (1999).

4. Malik, V., Sanjeev, N.K., and Hebbar, H.S. "Investigations on the effect of various tool pin profiles in friction stir welding using finite element simulations", Procedia Engineering., 97, pp. 1060-1068 (2014).

5. Akinlabi, E.D. Madyira, D.M., and Akinlabi, S. "Effect of heat input on the electrical resistivity of dissimilar friction stir welded joints of aluminium and copper", AFRICON IEEE., pp. 1-4 (2011).

6. Darras, B.M., Khraisheh, M.K., and Abu-Farha, F.K. "Friction stir processing of commercial AZ31 magnesium alloy", Journal of Materials Processing Technology., 191(1-3), pp. 77-81 (2007).

7. Avettand Fenoël, M.N., Taillard, R. Ji, G. and Goran, D. "Multiscale study of interfacial intermetallic compounds in a dissimilar $\mathrm{Al} 6082-\mathrm{T} 6 / \mathrm{Cu}$ friction-stir weld", Metallurgical and Materials, Transactions A., 43(12), pp. 4655-4666 (2012).

8. Yang, J., He, J., and Guan, X. "A probabilistic crack size quantification method using in-situ Lamb wave test and Bayesian updating", Mechanical Systems and Signal Processing., 78, pp. 118-133 (2016).

9. Hou, J.H., Liu, H.J., and Zhao, Y. "Influences of rotation speed on microstructures and mechanical properties of 6061-T6 aluminum alloy joints fabricated by self-reacting friction stir welding tool", 73(5-8), pp. 1073-1079 (2014).

10. Delir Nazarlou, R., Omidbakhsh, F., and Mollaei Milani, J. "Effect of rotational speed in friction stir welding on the material transfer mechanism in commercial pure aluminum", Journal of Welding Science and Technology of Iran, 6(1), pp. 9-17 (2020).

11. Anawa, E. and Olabi, A.G. "Using Taguchi method to optimize welding pool of dissimilar laser-welded components", Optics \& Laser Technology., 40(2), pp. 379-388 (2008). 
12. Chien, C.H., Lin, W.B., and Chen, T. "Optimal FSW process parameters for aluminum alloys AA5083", Journal of the Chinese Institute of Engineers., 34(1), pp. 99-105 (2011).

13. Ugrasen, G., Bharath, G., and Kumar, G.K. "Optimization of process parameters for Al6061-Al7075 alloys in friction stir welding using Taguchi's technique", Materials Today Proceedings., 5(1), pp. 30273035 (2018).

14. Sahu, P.K. and Pal, S. "Multi-response optimization of process parameters in friction stir welded AM20 magnesium alloy by Taguchi grey relational analysis", Journal of Magnesium and Alloys., 3(1), pp. 36-46 (2015).

15. Shunmugasundaram, M., Kumar, A.P., Sankar, L.P. "Optimization of process parameters of friction stir welded dissimilar AA6063 and AA5052 aluminum alloys by Taguchi technique", Materials Today Proceedings (2020).

16. Panda, M.R., Mahapatraand, S.S., and Mohanty, C.P. "Parametric investigation of friction stir welding on AA6061 using Taguchi technique", Materials Today Proceedings, 2(4-5), pp. 2399-2406 (2015).

17. Goyal, A. and Garg, R.K. "Establishing mathematical relationships to study tensile behavior of friction stir welded AA5086-H32 aluminium alloy joints", Silicon, 11(1), pp. 51-65 (2019).

18. Akhgar, B.N., Pazouki, M., and Ranjbar, M. "Application of Taguchi method for optimization of synthetic rutile nano powder preparation from ilmenite concentrate", Chemical Engineering Research and Design, 90(2), pp. 220-228 (2012).

19. Keleş, O. "An optimization study on the cementation of silver with copper in nitrate solutions by Taguchi design", Hydrometallurgy, 95(3-4), pp. 333-336 (2009).

20. Akinlabi, E.T., Akinlabi, S.A., and Surekha, K. "Effect of friction stir processing on the electrical resistivity of AA 6082", African IEEE, pp. 1-4 (2011).

21. Sharma, N., Khan, Z.A., Siddiquee, A.N. "Effect of process parameters on microstructure and electrical conductivity during FSW of Al-6101 and pure copper", Materials Research Express., 5(4), p. 046519 (2018).

22. Kahl, S. "Fatigue strength of friction stir welds in aluminium alloy AA6082-T6", TWI Friction Stir Welding Symposium (2010).

23. Kafali, H. and Ay, N. "Mechanical properties of 6013-T6 aluminium alloy friction stir welded plate", 13th International Conference Aerospace Sciences \& Aviation Technology (2009).

24. Wan, L., Huang, Y., and Wang, Y. "Friction stir welding of aluminium hollow extrusion: weld formation and mechanical properties", Materials Science and Technology, 31(12), pp. 1433-1442 (2015).
25. Lee, E.W., Oppenheim, T., and Robinson, K. "The effect of thermal exposure on the electrical conductivity and static mechanical behavior of several age hardenable aluminum alloys", Engineering Failure Analysis, 14(8), pp. 1538-1549 (2007).

26. Frigaard, $\phi$. , Grong, $\phi$. , and Midling, O. "A process model for friction stir welding of age hardening aluminum alloys", Metallurgical and Materials Transactions A, 32(5), pp. 1189-1200 (2001).

27. Gu, J., Ding, J., and Williams, S.W. "The effect of inter-layer cold working and post-deposition heat treatment on porosity in additively manufactured aluminum alloys", Journal of Materials Processing Technology, 230, pp. 26-34 (2016).

28. Silva, M.R., Gouyon, R., and Lepoutre, F. "Hidden corrosion detection in aircraft aluminum structures using laser ultrasonic and wavelet transform signal analysis", Ultrasonics, 41(4), pp. 301-305 (2003).

29. Liu, H.J., Fujii, H., and Maeda, M. "Tensile properties and fracture locations of friction-stir-welded joints of 2017-T351 aluminum alloy", Journal of Materials Processing Technology, 142(3), pp. 692-696 (2003).

\section{Biographies}

Ramin Delir Nazarlou is an MSc student of Mechanical Engineering at the Mechanical Engineering Department of Islamic Azad University, Tabriz branch. He is an expert in the mechanical and physical behavior of metallic materials. His main research interests are the welding and joining technology, nondestructive testing, and corrosion of the materials. He is particularly interested in issues concerning friction stir welding.

Behzad Nemati Akhgar is an Assistant Professor of Mining Science and Engineering at the Mining Engineering Department of the Engineering Faculty of Urmia University. His main research interests are the mining technology, nondestructive testing of materials, and surface mining.

Faraz Omidbakhsh is an Assistant Professor of Material Science and Engineering at the Mechanical Engineering Department of the Islamic Azad University, Tabriz branch. He is an expert in the mechanical and physical behavior of metallic materials. His main research interests are the fatigue fracture and micromechanics, oxidation of titanium alloys, Friction Stir Welding (FSW) of light alloys, and surface engineering. 